\title{
Oxidative decomposition of azo dye C.I. Acid Orange 7 (AO7) under microwave electrodeless lamp irradiation in the presence of $\mathrm{H}_{2} \mathrm{O}_{2}$
}

\author{
Xiwang Zhang*, Yizhong Wang, Guoting Li, Jiuhui Qu \\ State Key Laboratory of Environmental Aquatic Chemistry, Research Center for Eco-Environmental Sciences, \\ Chinese Academy of Sciences, Beijing 100085, PR China \\ Received 19 April 2005; received in revised form 26 October 2005; accepted 26 October 2005 \\ Available online 2 December 2005
}

\begin{abstract}
A novel microwave electrodeless lamp (MWL) rather than traditional electrode lamp (TEL) was used in a $\mathrm{H}_{2} \mathrm{O}_{2} / \mathrm{MWL}$ system as light source. This technique provided a new way to study the simultaneous effect of both UV-vis light and microwave irradiations. This study showed that $\mathrm{H}_{2} \mathrm{O}_{2}$ /MWL process was $32 \%$ more effective than $\mathrm{H}_{2} \mathrm{O}_{2}$ /TEL process in degrading azo dye Acid Orange 7 (AO7). Further study found that the degradation of $\mathrm{AO} 7$ by the $\mathrm{H}_{2} \mathrm{O}_{2} / \mathrm{MWL}$ process was initiated by the attack of $\mathrm{HO}^{\bullet}$ radicals generated by the photolysis of $\mathrm{H}_{2} \mathrm{O}_{2}$. However, the direct photolysis of AO7 by MWL irradiation was not negligible. Effect of operation parameters, such as the initial concentrations of AO7 and $\mathrm{H}_{2} \mathrm{O}_{2}$ and $\mathrm{pH}$, were investigated. A kinetic model of degradation of $\mathrm{AO} 7$ by $\mathrm{H}_{2} \mathrm{O}_{2} / \mathrm{MWL}$ process was found, in which not only the $\mathrm{HO}^{\bullet}$ oxidation but also direct photolysis were considered. The kinetic model was consistent with the experiment results. The degradation of $\mathrm{AO} 7$ by $\mathrm{H}_{2} \mathrm{O}_{2} / \mathrm{MWL}$ corresponded to a pseudo-first order reaction. The apparent reaction constant $\left(k_{\text {ap }}\right)$ was a function of initial concentrations of $\mathrm{H}_{2} \mathrm{O}_{2}$ and $\mathrm{AO} 7$ and $\mathrm{pH}$ of the solution.
\end{abstract}

(C) 2005 Elsevier B.V. All rights reserved.

Keywords: Microwave electrodeless lamp (MWL); $\mathrm{H}_{2} \mathrm{O}_{2}$; Acid Orange 7 (AO7); Kinetics

\section{Introduction}

Textile dyes and other industrial dyestuffs constitute one of the largest groups of organic compounds that represent an increasing environmental danger. The release of these colored wastewaters in the environment not only is a considerable source of non-aesthetic pollution and eutrophication but also can generate dangerous by-products through oxidation, hydrolysis, or other chemical reactions taking place in the wastewater phase. Due to the large degree of aromatics present in dye molecules and the stability of modern dyes, conventional biological treatment methods are ineffective for discoloration and degradation. Nevertheless, traditional physical techniques (adsorption on activated carbon, ultrafiltration, reverse osmosis, coagulation by chemical agents, ion exchange on synthetic adsorbent resins, etc.) just transfer organic compounds from water to another phase [1].

\footnotetext{
* Corresponding author. Tel.: +86 10 62849145; fax: +86 1062923541.

E-mail address: xiwangzhang@126.com (X. Zhang).
}

Advanced oxidation processes (AOPs) have received increasing attention in the last decade since they are able to deal with the problem of dye destruction in aqueous systems. AOPs are related to the formation of hydroxyl radicals $\left(\mathrm{HO}^{\bullet}\right)$, which will attack numerous organic compounds dissolved in wastewater quickly and nonselectively. AOPs such as Fenton and photoFenton catalytic reactions [2,3], $\mathrm{H}_{2} \mathrm{O}_{2} / \mathrm{UV}$ process [4,5] and photocatalysis [6,7] have been studied in order to reduce the color and organic load of dye-containing effluent wastewaters. Although heterogeneous photocatalysis is the most destructive emerging technology, the separation of $\mathrm{TiO}_{2}$ from the water is a difficult problem needing to be resolved. From this point of view, the use of homogeneous $\mathrm{H}_{2} \mathrm{O}_{2} / \mathrm{UV}$ appears to be a good alternative [8]. But, under UV irradiation, the molar extinction coefficient of hydrogen peroxide at $254 \mathrm{~nm}$ is only $19.6 \mathrm{M}^{-1} \mathrm{~s}^{-1}$. Therefore, in order to generate as many $\mathrm{HO}^{\bullet}$ radicals as possible, a large amount of hydrogen peroxide must be added into the reacting system [9].

Several studies have proved that microwaves can lead to the improvement of several types of oxidation processes. Kataoka et al. [10] found that the photocatalytic oxidation of ethylene 
proceeded faster $(83.9 \%)$ in the presence of the microwave irradiation than in the absence of it. Horikoshi et al. [11] illustrated that simultaneous photocatalysis and microwave radiation was more effective in the degradation of the Rhodamine-B dye than photocatalysis alone. Han et al. [9] showed that microwave irradiation could also considerably enhance the oxidative degradation of phenol in the $\mathrm{H}_{2} \mathrm{O}_{2} / \mathrm{UV}$ reacting system even under suppression of the thermal effect. Although microwaves effectively accelerate $\mathrm{H}_{2} \mathrm{O}_{2}$ /UV degradation efficiency, traditional electrode lamps (TELs) were not suitable to be laid in the microwave field because the metal electrodes of the lamp would be damaged under microwave irradiation. The problem will be solved if a microwave electrodeless lamp (MWL) substitutes TELs as light source. Círka and Hájek [12] applied MWL to the photochemical reaction of perfluorohexylethene with tetrahydrofuran. Comparative experiments with conventional mercury lamps showed the higher efficiency of microwave electrodeless lamps providing a high yield of product in a shorter reaction time. Klán et al. [13] also confirmed that MWL could feasibly be used in light-induced photofragmentation reaction valerophenone. Horihoshi et al. [14] found that an MWL was more effective in microwave-assisted photocatalytic degradation of 2,4-dichlorophenoxyacetic acid than an electrode $\mathrm{Hg}$ lamp.

The aim of this research was to evaluate whether the MWL could be useful to degrade wastewater in $\mathrm{UV} / \mathrm{H}_{2} \mathrm{O}_{2}$ process. Azo dye Acid Orange 7 (AO7) was used as the model compound to obtain detailed information of the novel process. Experimental optimization of the process and kinetics was examined.

\section{Experimental}

\subsection{Materials and analysis}

AO7 was obtained from Beijing Xuanwu Chemistry Co. and used without further purification. Unless otherwise indicated, the initial $\mathrm{pH}$ of solution was not adjusted. $\mathrm{H}_{2} \mathrm{O}_{2}(30 \%$, w/w, in $\mathrm{H}_{2} \mathrm{O}$ ) was purchased from Beijing Chemistry Co. All other chemicals used were analytical grade.

A Hitachi (UV-3010) spectrometer recording the spectra over the $200-650 \mathrm{~nm}$ range was used for the determination of AO7 concentration and to follow its kinetics of discoloration with irradiation time. The calibration curve was established to correlate the absorbance at $485 \mathrm{~nm}$ to $\mathrm{AO} 7$ concentration. The decrease of total organic carbon (TOC) was monitored by a TOC analyzer (Phoenix 8000, Tekmar-Dohrmann Co., USA). The concentration of $\mathrm{H}_{2} \mathrm{O}_{2}$ was measured by iodimetry.

\subsection{Estimation of power of microwave electrodeless lamp}

The power of an MWL cannot be measured directly just as traditional lamps. MWLs emit UV-vis light by absorbing microwave energy, so the power of an MWL equals the microwave power absorbed by it. In this experiment, the microwave power absorbed by the MWL could be measured by monitoring the temperature of the solution and the reactor with and without the MWL. Microwave irradiation can linearly raise the temperature of the solution and the reactor in the initial stage of reaction if the solution is not cooled by circulation. The slope obtained from the straight lines can be used to estimate the microwave power absorbed into the solution and the reactor by means of the following equation [9]:

$P=\left(c_{\mathrm{w}} m_{\mathrm{w}}+c_{\mathrm{r}} m_{\mathrm{r}}\right) \frac{\Delta T}{t}$

where $P$ is the microwave power absorbed by the solution and the reactor $(\mathrm{w}), m_{\mathrm{w}}$ and $m_{\mathrm{r}}$ are the mass of the solution and the reactor, $c_{\mathrm{W}}$ and $c_{\mathrm{r}}$ are the heat capacity of the solution and the reactor, $\Delta T$ is the temperature rise $\left({ }^{\circ} \mathrm{C}\right)$, and $t$ is the irradiation time (s). When the MWL is inside of the microwave oven and outside of the reactor, the microwave power absorbed by the solution and the reactor is defined as $P_{1}$. When the MWL is taken out from the system, the microwave power absorbed by the solution and the reactor is defined as $P_{2} . P_{1}$ is lower than $P_{2}$ because some microwave energy was absorbed by the MWL. $P_{1}$ and $P_{2}$ were 440.0 and $411.9 \mathrm{~W}$ in this system, respectively. It could be calculated that the power of the MWL was $28.1 \mathrm{~W}$. During reaction, the power of the MWL was less than $28.1 \mathrm{~W}$ because the microwave power absorbed by the MWL reduced to some extent due to the MWL being partially immersed in the solution.

\subsection{Degradation procedures}

The microwave source was a domestic microwave oven (Haier Co. Ltd.; power, $700 \mathrm{~W}$; frequency, $2.45 \mathrm{GHz}$ ), and the microwave was continuous during the reaction. The reactor was a cylindrical glass container $(D: 10 \mathrm{~cm} ; H: 15 \mathrm{~cm})$. Air $\left(0.15 \mathrm{~m}^{3} / \mathrm{h}\right)$ was bubbled through a sintered glass filter fixed at the bottom of the reactor and into the solution to mix the solution. The reactor was laid inside of the erect microwave oven as illustrated in Fig. 1. The solution temperature was kept at $38 \pm 1{ }^{\circ} \mathrm{C}$ by means of circulating solution to a cooler by a peristaltic pump. Seven hundred and fifty milliters $100 \mathrm{mg} / \mathrm{L}$ AO7 solution was added in the whole system, among which $125 \mathrm{~mL}$ was in the cooling circulation pipe and $625 \mathrm{~mL}$ was in the reactor. The MWL, which was made of quartz and filled with mercury and argon, was U-shaped. The UV-vis radiation emitted by the light source of the MWL is depicted in Fig. 2. The MWL floated on the solution and about $60 \%$ was immersed in solution.

In this study, we have performed comparative experiments of the MWL and a TEL. A 30-W ultraviolet lamp (Beijing ELR Co.) was used as the contrast, surrounded by a $5 \mathrm{~mm}$-thick quartz glass tube shell placed at the center of the reactor $(D: 9 \mathrm{~cm} ; H$ : $30 \mathrm{~cm})$.

In order to compare the effects of photolysis by microwave electrodeless lamp, direct reaction with $\mathrm{H}_{2} \mathrm{O}_{2}$ and degradation by $\mathrm{H}_{2} \mathrm{O}_{2} / \mathrm{UV}$, AO7 was degraded by employing the following three processes: (1) microwave electrodeless lamp irradiation alone (MWL); (2) direct reaction with $\mathrm{H}_{2} \mathrm{O}_{2}$ under microwave irradiation $\left(\mathrm{H}_{2} \mathrm{O}_{2} / \mathrm{MW}\right)$; (3) microwave-assisted $\mathrm{H}_{2} \mathrm{O}_{2} / \mathrm{UV}$-vis with an MWL as light source $\left(\mathrm{H}_{2} \mathrm{O}_{2} / \mathrm{MWL}\right)$. 

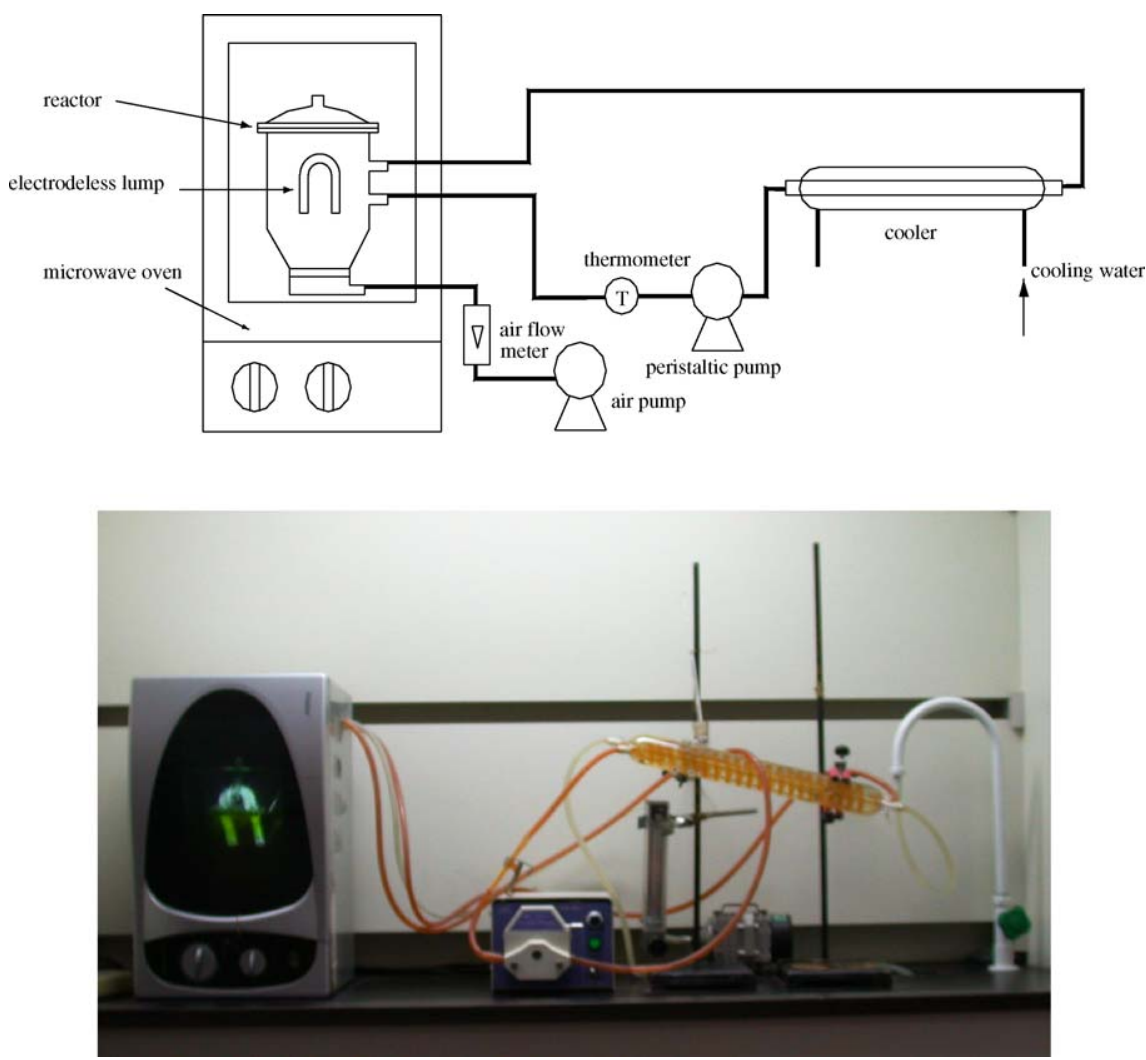

Fig. 1. Experimental set-up for $\mathrm{H}_{2} \mathrm{O}_{2} / \mathrm{MWL}$ degradation of $\mathrm{AO}$.

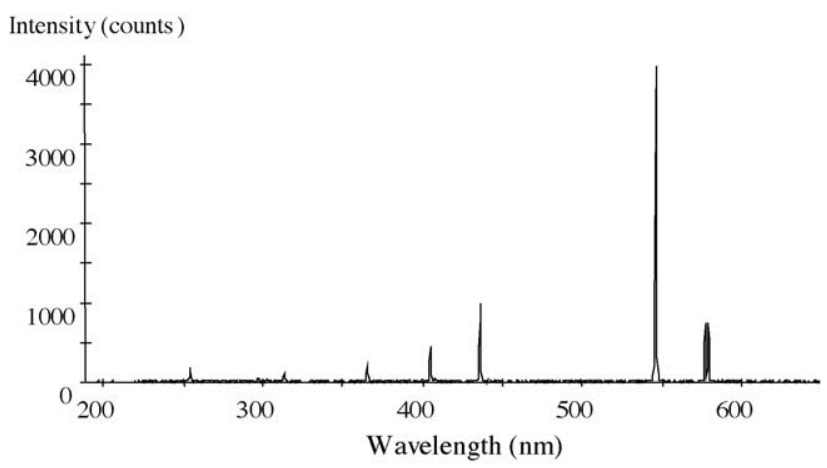

Fig. 2. Ultraviolet and visible wavelengths produced by the microwave electrodeless lamp.

\section{Results and discussion}

\subsection{Comparison of $M W L$ and TEL}

AO7 was degraded by $\mathrm{H}_{2} \mathrm{O}_{2} / \mathrm{MWL}$ and $\mathrm{H}_{2} \mathrm{O}_{2} /$ TEL under the same conditions, respectively. Fig. 3 indicates that the MWL is more effective than the TEL in AO7 degradation. From the pseudo first-order expression for the data of Fig. 3, the AO7 degradation rate constant of $\mathrm{H}_{2} \mathrm{O}_{2} / \mathrm{MWL}$ was found to be $32 \%$ higher than that of $\mathrm{H}_{2} \mathrm{O}_{2}$ /TEL. Fig. 2 shows that the light emission of MWL is mainly in the range of the visible region $(>400 \mathrm{~nm})$ and is much weaker in the UV region. Clearly, the better performance of the MWL is not due to light emission. Han et al. [9] considered that microwave irradiation induced a violent rotation and migration for the motion of polar molecules, which can lead the molecules to a more highly excited state resulting in acceleration of the rate of reactant decomposition. We cannot preclude synergism of microwave irradiation and light irradiation. Further study of the mechanism is under investigation.

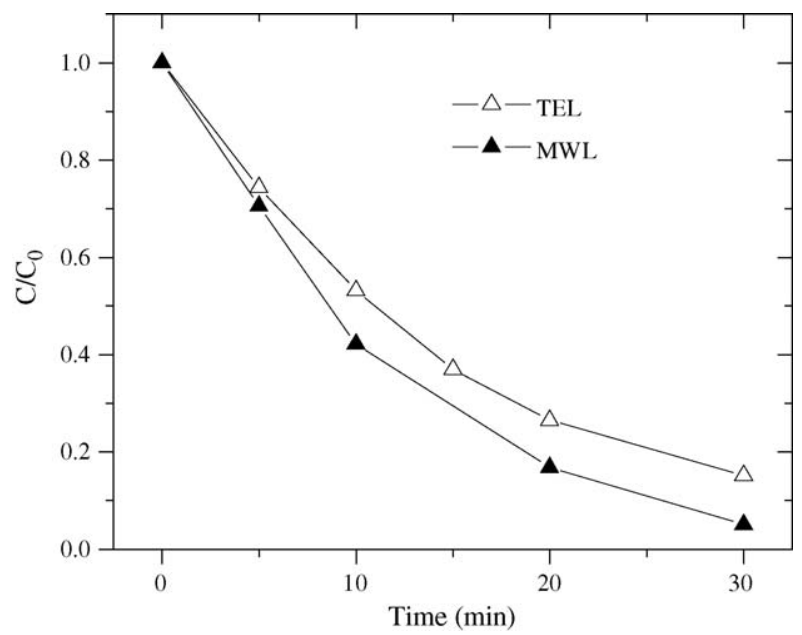

Fig. 3. Comparative experiments with microwave electrodeless lamp and traditional electrode lamp in $\mathrm{H}_{2} \mathrm{O}_{2} / \mathrm{UV}$ system. Experimental conditions: $[\mathrm{AO}]_{0}=100 \mathrm{mg} / \mathrm{L},\left[\mathrm{H}_{2} \mathrm{O}_{2}\right]_{0}=5 \mathrm{mmol} / \mathrm{L}$. 


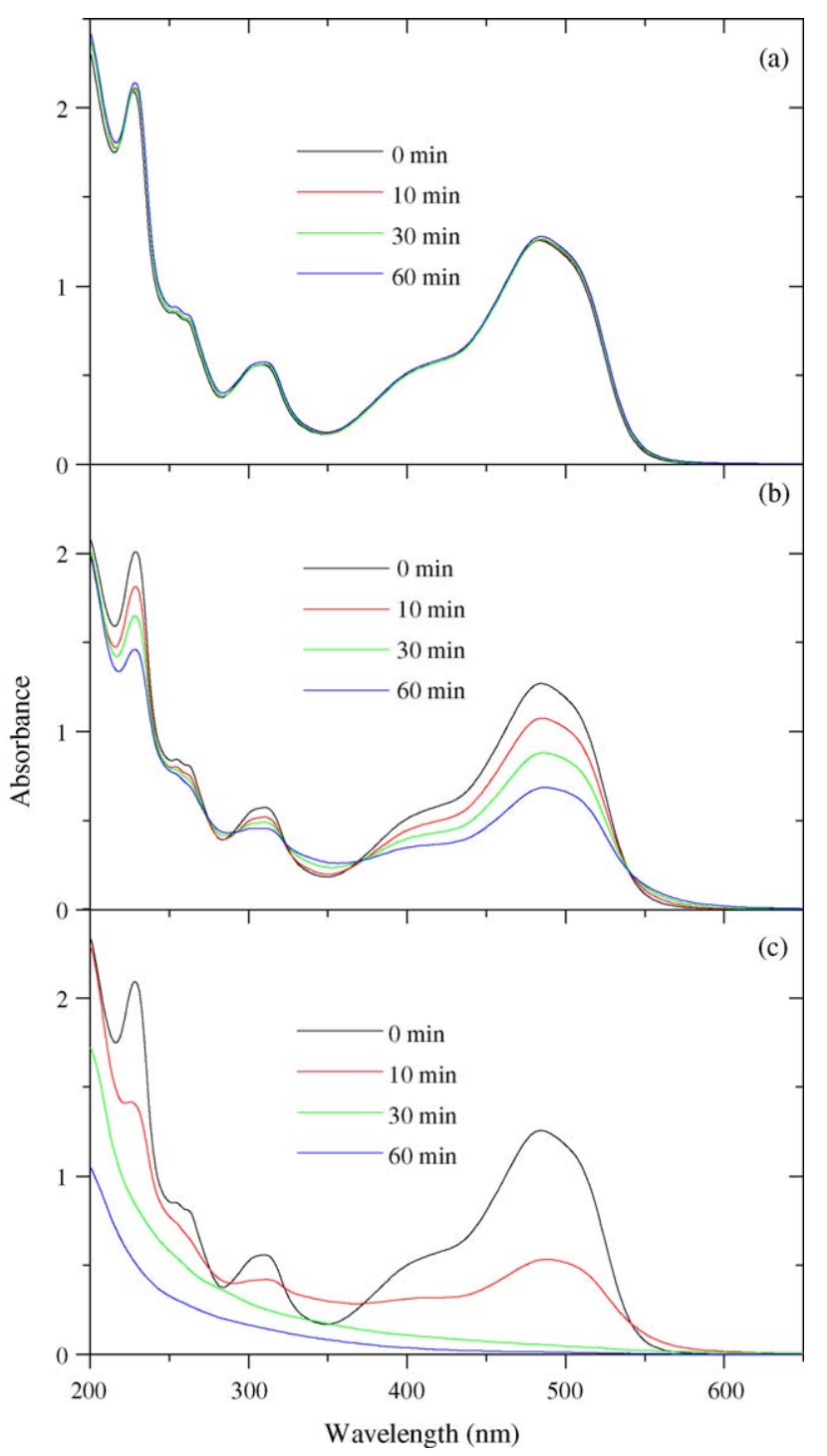

Fig. 4. UV-vis spectral changes of $\mathrm{AO} 7$ in solution as a function of irradiation time. (a) $\mathrm{H}_{2} \mathrm{O}_{2} / \mathrm{MW}$; (b) MWL; (c) $\mathrm{H}_{2} \mathrm{O}_{2} / \mathrm{MWL}$. Experimental conditions: $[\mathrm{AO} 7]_{0}=100 \mathrm{mg} / \mathrm{L},\left[\mathrm{H}_{2} \mathrm{O}_{2}\right]_{0}=5 \mathrm{mmol} / \mathrm{L}$, initial pH 7.2 (natural). Insert: 2.5fold diluted.

\subsection{UV-vis spectral changes of AO7 solution with irradiation time}

Fig. 4 shows typical UV-vis spectra obtained during $\mathrm{H}_{2} \mathrm{O}_{2} / \mathrm{MWL}, \mathrm{H}_{2} \mathrm{O}_{2} / \mathrm{MW}$ and MWL degradation of aqueous solutions of AO7. No degradation of AO7 within $60 \mathrm{~min}$ occurred by $\mathrm{H}_{2} \mathrm{O}_{2} / \mathrm{MW}$ (Fig. 4(a)). However, irradiation of MWL alone (Fig. 4(b)) led to about $45 \%$ of AO7 being transformed after this time. With the $\mathrm{H}_{2} \mathrm{O}_{2}$ /MWL (Fig. 4(c)), about $95 \%$ of AO7 solution was discolored after only $30 \mathrm{~min}$, with the solution displaying no spectral features. The absorption spectrum features of $\mathrm{AO} 7$ at 485, 310 and $228 \mathrm{~nm}$ correlate with the structural features of azo linkage, naphthalene and benzene rings of AO7, respectively [15]. The relevant first-order kinetics of the transformation of $\mathrm{AO} 7$ at three spectral wavelengths are listed in Table 1. These data show that $\mathrm{H}_{2} \mathrm{O}_{2}$ /MWL is more effective than MWL irradiation alone in degradation of AO7. The ratios
Table 1

Summary of rates of discoloration of AO7 solution by the three methods used

\begin{tabular}{|c|c|c|c|}
\hline Degradation method & $\begin{array}{l}k_{228 \mathrm{~nm}} \\
\left(10^{-2} \min ^{-1}\right)\end{array}$ & $\begin{array}{l}k_{310 \mathrm{~nm}} \\
\left(10^{-2} \min ^{-1}\right)\end{array}$ & $\begin{array}{l}k_{485 \mathrm{~nm}} \\
\left(10^{-2} \mathrm{~min}^{-1}\right)\end{array}$ \\
\hline $\mathrm{H}_{2} \mathrm{O}_{2} / \mathrm{MW}$ & - & - & - \\
\hline MWL & 0.47 & 0.31 & 0.97 \\
\hline $\mathrm{H}_{2} \mathrm{O}_{2} / \mathrm{MWL}$ & 2.16 & 2.09 & 8.45 \\
\hline Ratio $\left(k_{\mathrm{H}_{2} \mathrm{O}_{2} / \mathrm{MWL}} / k_{\mathrm{MWL}}\right)$ & 4.6 & 6.7 & 8.7 \\
\hline
\end{tabular}

of the disappearance kinetics at the three spectral wavelengths in the $\mathrm{H}_{2} \mathrm{O}_{2} / \mathrm{MWL}$ are $k_{228 \mathrm{~nm}} / k_{310 \mathrm{~nm}} / k_{485 \mathrm{~nm}}=1 / 1.0 / 3.9$. These ratios imply that degradation in the $\mathrm{H}_{2} \mathrm{O}_{2} / \mathrm{MWL}$ method are different from those in the MWL photolytic degradation for $\mathrm{AO} 7$, inasmuch as the relevant ratios for the latter method are $k_{228 \mathrm{~nm}} / k_{310 \mathrm{~nm}} / k_{485 \mathrm{~nm}}=1 / 0.7 / 2.1$.

\subsection{Temporal changes of $p H$}

Fig. 5 shows temporal changes of $\mathrm{pH}$ during $\mathrm{H}_{2} \mathrm{O}_{2} / \mathrm{MWL}$, $\mathrm{H}_{2} \mathrm{O}_{2}$ /MW and MWL degradation of aqueous solutions of AO7. $\mathrm{H}_{2} \mathrm{O}_{2}$ /MWL caused significant decrease of the $\mathrm{pH}$ during $60 \mathrm{~min}$ reaction, from $\mathrm{pH} 7.2$ at $t=0$ to ca. $\mathrm{pH} 3.8$ at $t=60 \mathrm{~min}$. MWL irradiation has less effect on $\mathrm{pH}$, which at the end of the experiment reached the value of 6.6. The $\mathrm{pH}$ was not changed by $\mathrm{H}_{2} \mathrm{O}_{2} / \mathrm{MW}$. The drop of $\mathrm{pH}$ with time was associated with the formation of acid products. This indicates that $\mathrm{H}_{2} \mathrm{O}_{2} / \mathrm{MWL}$ destroyed AO7 to small molecular products more effectively than MWL irradiation alone.

\subsection{Temporal change of total organic carbon}

Total organic carbon (TOC) values are the total concentration of organics in solution and the changes of TOC mirror the degree of mineralization as a function of irradiation time. Results of TOC measurements obtained during the three treatment methods of aqueous solution of AO7 are presented in Fig. 6. It was

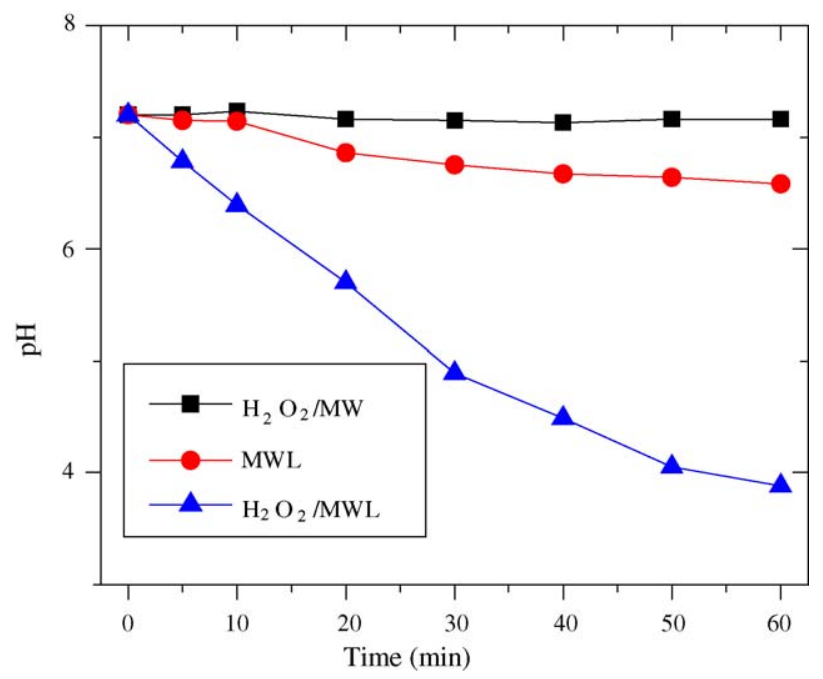

Fig. 5. Change of $\mathrm{pH}$ of solution with irradiation time. Experimental conditions: $[\mathrm{AO} 7]_{0}=100 \mathrm{mg} / \mathrm{L},\left[\mathrm{H}_{2} \mathrm{O}_{2}\right]_{0}=5 \mathrm{mmol} / \mathrm{L}$, initial $\mathrm{pH} 7.2$ (natural). 


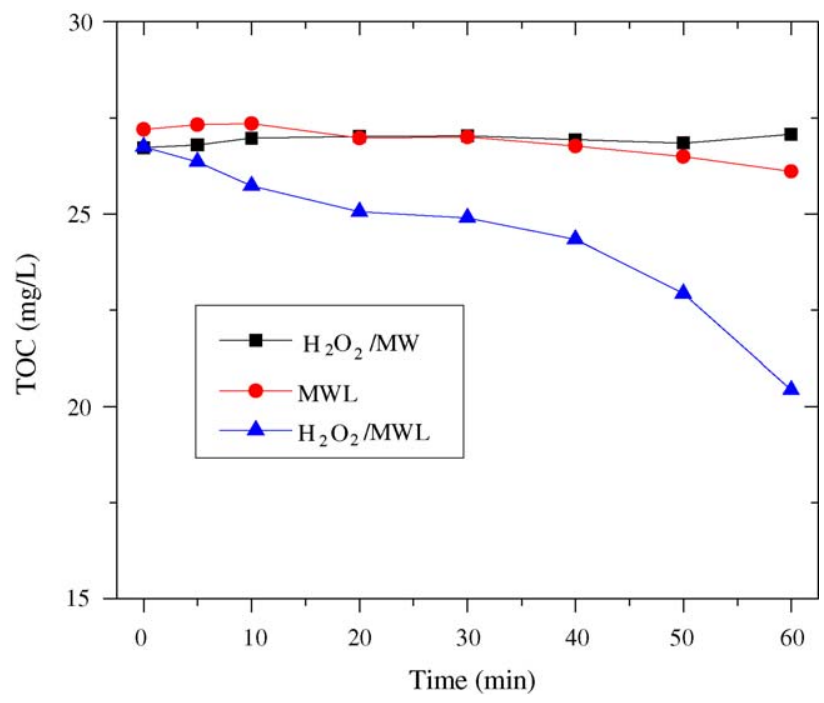

Fig. 6. Change of TOC of solution with irradiation time. Experimental conditions: $[\mathrm{AO} 7]_{0}=100 \mathrm{mg} / \mathrm{L},\left[\mathrm{H}_{2} \mathrm{O}_{2}\right]_{0}=5 \mathrm{mmol} / \mathrm{L}$, initial $\mathrm{pH} 7.2$ (natural).

observed that TOC was also not influenced by $\mathrm{H}_{2} \mathrm{O}_{2} / \mathrm{MW}$. MWL irradiation also had a bad performance on mineralization. Even after 60 min irradiation, less than $2 \%$ TOC was removed. By contrast, decay of TOC by $\mathrm{H}_{2} \mathrm{O}_{2} / \mathrm{MWL}$ was more significant. About $30 \%$ TOC was removed after same time. However, in the initial $30 \mathrm{~min}$, the rate of TOC removal also was very low in $\mathrm{H}_{2} \mathrm{O}_{2} / \mathrm{MWL}$. Less than $7 \%$ TOC is removed, whereas the color removal ratio reaches $95 \%$ more. After $30 \mathrm{~min}$, the rate of TOC removal markedly increased. At that time, the AO7 solution was almost discolored completely. Clearly, this indicated that discoloration was the first degradation step.

\subsection{Temporal change of $\mathrm{H}_{2} \mathrm{O}_{2}$ concentration}

Fig. 7 shows the temporal change of $\mathrm{H}_{2} \mathrm{O}_{2}$ concentration in $\mathrm{H}_{2} \mathrm{O}_{2}$ /MWL. The $\mathrm{H}_{2} \mathrm{O}_{2}$ concentration decreased linearly

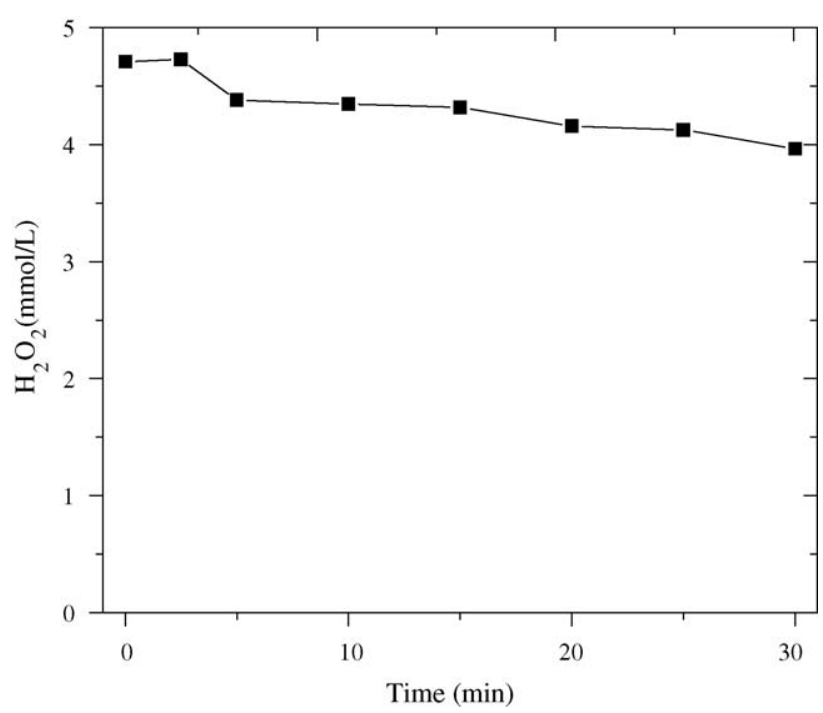

Fig. 7. Change of $\mathrm{H}_{2} \mathrm{O}_{2}$ concentration with irradiation time. Experimental conditions: $[\mathrm{AO} 7]_{0}=100 \mathrm{mg} / \mathrm{L},\left[\mathrm{H}_{2} \mathrm{O}_{2}\right]_{0}=5 \mathrm{mmol} / \mathrm{L}$, initial pH 7.2 (natural).
Table 2

Pseudo-first order rate constants for discoloration of $\mathrm{AO} 7$ by $\mathrm{H}_{2} \mathrm{O}_{2} / \mathrm{MWL}$ at different initial concentrations of $\mathrm{AO} 7$ and $\mathrm{H}_{2} \mathrm{O}_{2}$ and various pHs

\begin{tabular}{rccccc}
\hline No. & $\begin{array}{l}{\left[\mathrm{H}_{2} \mathrm{O}_{2}\right]_{0}} \\
(\mathrm{mmol} / \mathrm{L})\end{array}$ & {$[\mathrm{AO} 7]_{0}(\mathrm{mg} / \mathrm{L})$} & $\mathrm{pH}$ & $k_{\mathrm{ap}}\left(10^{-2} \mathrm{~min}^{-1}\right)$ & $R^{2}$ \\
\hline 1 & 5 & 80 & 7.2 & 15.91 & 0.999 \\
2 & 5 & 100 & 7.2 & 8.45 & 0.994 \\
3 & 5 & 170 & 7.2 & 4.96 & 0.993 \\
4 & 5 & 250 & 7.2 & 2.83 & 0.991 \\
5 & 1 & 100 & 7.2 & 4.28 & 0.999 \\
6 & 2 & 100 & 7.2 & 5.09 & 0.998 \\
7 & 4 & 100 & 7.2 & 8.31 & 0.999 \\
8 & 12 & 100 & 7.2 & 16.05 & 0.999 \\
9 & 20 & 100 & 7.2 & 14.17 & 0.992 \\
10 & 5 & 100 & 3 & 10.65 & 0.992 \\
11 & 5 & 100 & 5 & 9.07 & 0.999 \\
12 & 5 & 100 & 9 & 7.34 & 0.992 \\
13 & 5 & 100 & 11 & 6.62 & 0.998 \\
\hline
\end{tabular}

with reaction time. At $30 \mathrm{~min}$, the $\mathrm{H}_{2} \mathrm{O}_{2}$ concentration reduced $0.75 \mathrm{mmol} / \mathrm{L}$. At same time, $0.27 \mathrm{mmol} / \mathrm{L} \mathrm{AO} 7$ was discolored. This indicated that $1 \mathrm{~mol} \mathrm{AO7} \mathrm{discoloration} \mathrm{consumed} 2.8 \mathrm{~mol}$ $\mathrm{H}_{2} \mathrm{O}_{2}$.

\subsection{Effect of operation parameters}

\subsubsection{Effect of initial AO7 concentration}

It is important from an application point of view to study the dependence of removal efficiency on the initial concentration of dye. Table 2 shows the degradation of $\mathrm{AO} 7$ at four different initial concentrations (the concentration of $\mathrm{H}_{2} \mathrm{O}_{2}$ was $5 \mathrm{mmol} / \mathrm{L}$ for all runs); Increase in the initial concentration of dye from 80 to $250 \mathrm{mg} / \mathrm{L}$ decreased the discoloration apparent reaction constant from $15.91 \times 10^{-2}$ to $2.83 \times 10^{-2} \mathrm{~min}^{-1}$. The rise in dye concentration induced an inner filter effect on light. Consequently, the solution became more and more impermeable to UV radiation with increasing of initial dye concentration and lowed hydroxyl radicals concentration [16]. Moreover, at higher dye concentrations, higher concentrations of intermediates were formed. These intermediates were also highly reactive toward hydroxyl radicals.

\subsubsection{Effect of $\mathrm{H}_{2} \mathrm{O}_{2}$ dosage}

The $\mathrm{H}_{2} \mathrm{O}_{2}$ concentration is crucial for the degradation rate. The rate of degradation increased with increasing concentrations of hydrogen peroxide as Table 2 shows. The addition of $\mathrm{H}_{2} \mathrm{O}_{2}$ from 1 to $12 \mathrm{mmol} / \mathrm{L}$ increased the discoloration $k_{\text {ap }}$ from $4.28 \times 10^{-2}$ to $16.05 \times 10^{-2} \mathrm{~min}^{-1}$. The reason for this is that at higher concentrations of hydrogen peroxide, more UV is absorbed by hydrogen peroxide and the rate of hydroxyl radicals is higher, which leads to a higher rate of oxidation of AO7. However, above $12 \mathrm{mmol} / \mathrm{L}$, the rate of degradation decreased with increasing concentrations of hydrogen peroxide. Increase of $\mathrm{H}_{2} \mathrm{O}_{2}$ concentration from 12 to $20 \mathrm{mmol} / \mathrm{L}$ decreased the discoloration $k_{\text {ap }}$ from $16.05 \times 10^{-2}$ to $14.17 \times 10^{-2} \mathrm{~min}^{-1}$. At high concentrations, $\mathrm{H}_{2} \mathrm{O}_{2}$ acts as a hydroxyl radical quencher as follows, consequently lowering the concentration of hydroxyl 
radicals [17]:

$$
\begin{aligned}
& \mathrm{HO}^{\bullet}+\mathrm{H}_{2} \mathrm{O}_{2} \rightarrow \mathrm{HO}_{2}^{\bullet}+\mathrm{H}_{2} \mathrm{O} \\
& \mathrm{HO}^{\bullet}+\mathrm{HO}_{2}^{\bullet} \rightarrow \mathrm{H}_{2} \mathrm{O}+\mathrm{O}_{2}
\end{aligned}
$$

\subsubsection{Effect of initial $p H$}

The effect of $\mathrm{pH}$ on discoloration was studied in the $\mathrm{pH}$ range 3-11. The results are shown in Table 2. The $\mathrm{pH}$ of solution was adjusted using $\mathrm{H}_{2} \mathrm{SO}_{4}$ and $\mathrm{NaOH}$. From the results, it is clear that the process is more efficient in acid medium $(\mathrm{pH} 3)$. Increase of $\mathrm{pH}$ from 3 to 11 decreased the discoloration $k_{\mathrm{ap}}$ from $10.65 \times 10^{-2}$ to $6.62 \times 10^{-2} \mathrm{~min}^{-1}$. Muruganandham and Swaminathan [17] also found that $\mathrm{H}_{2} \mathrm{O}_{2} / \mathrm{UV}$ discoloration of azo dye Reactive Orange 4 was more efficient in acid medium $(\mathrm{pH}=2-4)$ and further increase of $\mathrm{pH}$ from 3 to 8 decreased the discoloration. He considered that the lowering of the removal rate in this $\mathrm{pH}$ range was due to a reduction of hydroxyl radical concentration. Under this condition $\mathrm{H}_{2} \mathrm{O}_{2}$ undergoes photodecomposition to water and oxygen rather than hydroxyl radical (Eq. (27)):

$2 \mathrm{H}_{2} \mathrm{O}_{2}+h v \rightarrow 2 \mathrm{H}_{2} \mathrm{O}+\mathrm{O}_{2}$

\subsection{Kinetic study}

From the data above, it is clear that the degradation of $\mathrm{AO} 7$ by the $\mathrm{H}_{2} \mathrm{O}_{2} / \mathrm{MWL}$ system is initiated by the attack of $\mathrm{HO}^{\bullet}$ radicals generated by photolysis of $\mathrm{H}_{2} \mathrm{O}_{2}$. However, the direct photolysis of $\mathrm{AO} 7$ by MWL irradiation is not negligible, which is different from traditional electrode lamp irradiation. Hydroxyl radicals may react with $\mathrm{AO} 7, \mathrm{H}_{2} \mathrm{O}_{2}$, and the intermediate products of the degradation process. From the initial oxidation of the AO7 until complete mineralization, a complex set of reactions took place. The following main reactions may be considerated:

$$
\begin{aligned}
& \mathrm{H}_{2} \mathrm{O}_{2}+h v \rightarrow 2 \mathrm{HO}^{\bullet}, \quad I_{\mathrm{HP}} \Phi_{\mathrm{HP}} \\
& \mathrm{H}_{2} \mathrm{O}_{2}+\mathrm{HO}^{\bullet} \rightarrow \mathrm{HO}_{2}^{\bullet}+\mathrm{H}_{2} \mathrm{O}, \quad k_{\mathrm{HP}} \\
& \mathrm{S}+h v \rightarrow \text { Int, } \quad I_{\mathrm{S}} \Phi_{\mathrm{S}} \\
& \mathrm{S}+\mathrm{HO}^{\bullet} \rightarrow \text { Int, } \quad k_{\mathrm{S}} \\
& \text { Int }+\mathrm{HO}^{\bullet} \rightarrow \mathrm{P}, \quad k_{\text {Int }}
\end{aligned}
$$

where $I_{\mathrm{HP}}$ and $I_{\mathrm{S}}$ are the rates of photons absorbed by $\mathrm{H}_{2} \mathrm{O}_{2}$ and the substrate $\mathrm{AO} 7$, respectively. $\Phi_{\mathrm{HP}}$ and $\Phi_{\mathrm{S}}$ are the quantum yields of respective photolysis. $k_{\mathrm{HP}}, k_{\mathrm{S}}$ and $k_{\text {Int }}$ are the bimolecular rate constants for the corresponding reactions with hydroxyl radicals. In this reaction scheme, reactions implying $\mathrm{HO}_{2}{ }^{\bullet}$ or $\mathrm{O}_{2}{ }^{-\bullet}$ radicals have not been considered, as their reactivity is much lower than that of $\mathrm{HO}^{\bullet}[18]$.

Considering the simplified mechanism proposed, the rate of AO7 consumption $(r)$ is given by the sum of the rates of direct photolysis reaction (7) and reaction with $\mathrm{HO}^{\bullet}(8)$ :

$r=-\frac{\mathrm{d}[\mathrm{S}]}{\mathrm{d} t}=I_{\mathrm{S}} \Phi_{\mathrm{S}}+k_{\mathrm{S}}[\mathrm{S}]\left[\mathrm{HO}^{\bullet}\right]$
The net rate of formation of $\mathrm{HO}^{\bullet}$ can be derived by the reactions (5), (6), (8) and (9) as follows:

$$
\begin{aligned}
r_{[\mathrm{OH}]}= & \frac{\mathrm{d}[\mathrm{HO}]^{\bullet}}{\mathrm{d} t}=2 I_{\mathrm{HP}} \Phi_{\mathrm{HP}}-k_{\mathrm{HP}}\left[\mathrm{H}_{2} \mathrm{O}_{2}\right]\left[\mathrm{HO}^{\bullet}\right] \\
& -k_{\mathrm{S}}[\mathrm{S}]\left[\mathrm{HO}^{\bullet}\right]-k_{\mathrm{Int}}[\mathrm{Int}]\left[\mathrm{HO}^{\bullet}\right]
\end{aligned}
$$

With the steady-state approximation for Eq. (11), the concentration of $\mathrm{HO}^{\bullet}$ is given by Eq. (12):

$$
\left[\mathrm{HO}^{\bullet}\right]=\frac{2 I_{\mathrm{HP}} \phi_{\mathrm{HP}}}{k_{\mathrm{HP}}\left[\mathrm{H}_{2} \mathrm{O}_{2}\right]+k_{\mathrm{S}}[\mathrm{S}]+k_{\text {Int }}[\text { Int }]}
$$

So, the oxidation rate of the substrate $(r)$ is expressed as:

$r=I_{\mathrm{S}} \Phi_{\mathrm{S}}+\frac{2 I_{\mathrm{HP}} \phi_{\mathrm{HP}} k_{\mathrm{S}}[\mathrm{S}]}{k_{\mathrm{HP}}\left[\mathrm{H}_{2} \mathrm{O}_{2}\right]+k_{\mathrm{S}}[\mathrm{S}]+k_{\mathrm{Int}}[\mathrm{Int}]}$

In the early stage of the degradation (decolorization stage), decolorization is much faster than mineralization. So, we can write:

$[\mathrm{S}]_{0} \approx[\mathrm{S}]+[\mathrm{Int}]$

The difference between $k_{\mathrm{S}}$ and $k_{\text {Int }}$ was supposed to be negligible $\left(k_{\mathrm{S}} \approx k_{\text {Int }}\right)[16]$. Hence it can be written as:

$k_{\mathrm{S}}[\mathrm{S}]+k_{\text {Int }}[\mathrm{Int}]=k_{\mathrm{S}}[\mathrm{S}]_{0}$

According to Lambert-Beer's law,

$$
\begin{aligned}
& I_{\mathrm{S}}=I_{0}\left(1-10^{-A}\right) \frac{\varepsilon_{\mathrm{S}}[S]}{\sum \varepsilon_{i} C_{i}} \\
& I_{\mathrm{HP}}=I_{0}\left(1-10^{-A}\right) \frac{\varepsilon_{\mathrm{HP}}\left[\mathrm{H}_{2} \mathrm{O}_{2}\right]}{\sum \varepsilon_{i} C_{i}} \\
& A=\exp \left(-2.3 L\left(\varepsilon_{\mathrm{HP}}\left[\mathrm{H}_{2} \mathrm{O}_{2}\right]+\varepsilon_{\mathrm{S}}[\mathrm{S}]+\varepsilon_{\mathrm{Int}}[\mathrm{Int}]\right)\right) \\
& \sum \varepsilon_{i} C_{i}=\varepsilon_{\mathrm{HP}}\left[\mathrm{H}_{2} \mathrm{O}_{2}\right]+\varepsilon_{\mathrm{S}}[\mathrm{S}]+\varepsilon_{\mathrm{Int}}[\mathrm{Int}]
\end{aligned}
$$

where $I_{0}$ is the incident UV-light intensity, $L$ is the optical path length of the system; $\varepsilon_{\mathrm{HP}}, \varepsilon_{\mathrm{S}}$ and $\varepsilon_{\text {Int }}$ are the molar extinction coefficients for $\mathrm{H}_{2} \mathrm{O}_{2}, \mathrm{AO} 7$ and the intermediate product, respectively. Due to the high absorbance of the $\mathrm{AO} 7$ and $\mathrm{H}_{2} \mathrm{O}_{2}$ in the process, it can be written as:

$\left(1-10^{-A}\right) \approx 1$

The difference between $\varepsilon_{\mathrm{S}}$ and $\varepsilon_{\mathrm{Int}}$ was supposed to be negligible $\left(\varepsilon_{\mathrm{S}} \approx \varepsilon_{\text {Int }}\right)$. Hence it can be written as:

$\varepsilon_{\mathrm{S}}[\mathrm{S}]+\varepsilon_{\text {Int }}[$ Int $]=\varepsilon_{\mathrm{S}}[\mathrm{S}]_{0}$

So, the oxidation rate of the substrate $(r)$ is simplified as:

$r=\frac{I_{0}}{\varepsilon_{\mathrm{HP}}\left[\mathrm{H}_{2} \mathrm{O}_{2}\right]+\varepsilon_{\mathrm{S}}[\mathrm{S}]_{0}}\left\{\varepsilon_{\mathrm{S}} \phi_{\mathrm{S}}+\frac{2 k_{\mathrm{S}} \varepsilon_{\mathrm{HP}} \phi_{\mathrm{HP}}\left[\mathrm{H}_{2} \mathrm{O}_{2}\right]}{k_{\mathrm{HP}}\left[\mathrm{H}_{2} \mathrm{O}_{2}\right]+k_{\mathrm{S}}[\mathrm{S}]_{0}}\right\}[\mathrm{S}]$

If

$\frac{I_{0}}{\varepsilon_{\mathrm{HP}}\left[\mathrm{H}_{2} \mathrm{O}_{2}\right]+\varepsilon_{\mathrm{S}}[\mathrm{S}]_{0}}\left\{\varepsilon_{\mathrm{S}} \phi_{\mathrm{S}}+\frac{2 k_{\mathrm{S}} \varepsilon_{\mathrm{HP}} \phi_{\mathrm{HP}}\left[\mathrm{H}_{2} \mathrm{O}_{2}\right]}{k_{\mathrm{HP}}\left[\mathrm{H}_{2} \mathrm{O}_{2}\right]+k_{\mathrm{S}}[\mathrm{S}]_{0}}\right\}=k_{\mathrm{ap}}$ 
Eq. (22) is simplified as following:

$r=k_{\mathrm{ap}}[\mathrm{S}]$

where $k_{\mathrm{ap}}$ is the apparent reaction constant of substrate $\mathrm{AO} 7$ degradation. Mostly, $\left[\mathrm{H}_{2} \mathrm{O}_{2}\right]_{0} \gg[\mathrm{S}]_{0}$. One mole AO7 discoloration consumes $2.8 \mathrm{~mol} \mathrm{H}_{2} \mathrm{O}_{2}$. Hence it can be written as:

$\left[\mathrm{H}_{2} \mathrm{O}_{2}\right]=\left[\mathrm{H}_{2} \mathrm{O}_{2}\right]_{0}-2.8\left([\mathrm{~S}]_{0}-[\mathrm{S}]\right) \approx\left[\mathrm{H}_{2} \mathrm{O}_{2}\right]_{0}$

So,

$k_{\mathrm{ap}}=\frac{I_{0}}{\varepsilon_{\mathrm{HP}}\left[\mathrm{H}_{2} \mathrm{O}_{2}\right]_{0}+\varepsilon_{\mathrm{S}}[\mathrm{S}]_{0}}\left\{\varepsilon_{\mathrm{S}} \phi_{\mathrm{S}}+\frac{2 k_{\mathrm{S}} \varepsilon_{\mathrm{HP}} \phi_{\mathrm{HP}}\left[\mathrm{H}_{2} \mathrm{O}_{2}\right]_{0}}{k_{\mathrm{HP}}\left[\mathrm{H}_{2} \mathrm{O}_{2}\right]_{0}+k_{\mathrm{S}}[\mathrm{S}]_{0}}\right\}$

This kinetic model indicates that the degradation of AO7 corresponds to a pseudo-first order reaction, which is consistent with the experiment results above. It can also be concluded that the apparent reaction constant $\left(k_{\mathrm{ap}}\right)$ is a function of the initial concentration of $\mathrm{H}_{2} \mathrm{O}_{2}$ and $\mathrm{AO}$. As discussed above, $\mathrm{pH}$ also affects the degradation of AO7. In this kinetic model, the effect of $\mathrm{pH}$ on $k_{\mathrm{ap}}$ was reflected by variation of some parameters with $\mathrm{pH}$ change, such as $k_{\mathrm{HP}}, k_{\mathrm{S}}, \Phi_{\mathrm{HP}}$ and $\Phi_{\mathrm{S}}$.

\section{Conclusion}

Although the MWL used in our experiment has a weak UV region, our study has displayed that MWL as the light source is more effective in the $\mathrm{UV}-\mathrm{vis} / \mathrm{H}_{2} \mathrm{O}_{2}$ system than TEL to treat wastewaters. Other research [19] found that light intensity and irradiation wavelengths of MWL could be adjusted according to requirement. The lamp even gave over three times as much UV radiation as the traditional electrode lamp [12]. The simultaneous irradiation of polluted water by both $\mathrm{MW}$ and $\mathrm{UV}$-vis light makes it possible to use the simplified effective $\mathrm{H}_{2} \mathrm{O}_{2}$ /MWL for practical application. On the basis of the proposed kinetic model, the pseudo-first rate constant $\left(k_{\mathrm{ap}}\right)$ is affected by varying the initial concentration of $\mathrm{AO} 7, \mathrm{H}_{2} \mathrm{O}_{2}$ and $\mathrm{pH}$, which is consistent with the experiment results.

\section{Acknowledgements}

The authors appreciate the generous financial support of this work by the Chinese Funds for 863 Project (2002AA601300) and thank Wuhan University of Science and Engineering for their help in the experiment.

\section{References}

[1] I.K. Konstantinou, T.A. Albanis, $\mathrm{TiO}_{2}$-assisted photocatalytic degradation of azo dyes in aqueous solution: kinetic and mechanistic investigations, Appl. Catal. B: Environ. 49 (2004) 1-14.
[2] M. Pérez, F. Torrades, X. Domènech, J. Peral, Fenton and photo-fenton oxidation of textile effluents, Water Res. 36 (2002) 3237-3244.

[3] X.R. Xu, H.B. Li, W.H. Wang, J.D. Gu, Degradation of dyes in aqueous solutions by the Fenton process, Chemosphere 57 (2004) 595-600.

[4] C. Galindo, A. Kalt, $\mathrm{UV} / \mathrm{H}_{2} \mathrm{O}_{2}$ oxidation of azodyes in aqueous media: evidence of a structure-degradability relationship, Dyes Pigments 42 (1999) 199-207.

[5] M. Neantu, I. Siminiceanu, A. Yediler, A. Kettrup, Kinetics of decolorization and mineralization of reactive azo dyes in aqueous solution by the UV/ $\mathrm{H}_{2} \mathrm{O}_{2}$ oxidation, Dyes Pigments 53 (1999) 93-99.

[6] G. Liu, T. Wu, J. Zhao, H. Hidaka, N. Serpone, Photoassisted degradation of dye pollutants 8 . Irreversible degradation of alizarin red under visible light radiation in air-equilibrated aqueous $\mathrm{TiO}_{2}$ dispersions, Environ. Sci. Technol. 33 (1999) 2081-2087.

[7] J. Zhao, T. Wu, K. Wu, K. Oikawa, H. Hidaka, N. Serpone, Photoassisted degradation of dye pollutant 3. Degradation of the cationic dye rhodamine $\mathrm{B}$ in aqueous anionic surfactant/TiO $\mathrm{T}_{2}$ dispersions under visible light irradiation: evidence for the need of substrate adsorption on $\mathrm{TiO}_{2}$ particles, Environ. Sci. Technol. 32 (1998) 2394-2400.

[8] P.K. Malik, S.K. Sanyal, Kinetics of decolorisation of azo dyes in wastewater by $\mathrm{UV} / \mathrm{H}_{2} \mathrm{O}_{2}$ process, Separat. Purif. Technol. 36 (2004) $167-175$.

[9] D.H. Han, S.Y. Cha, H.Y. Yang, Improvement of oxidative decomposition of aqueous phenol by microwave irradiation in $\mathrm{UV} / \mathrm{H}_{2} \mathrm{O}_{2}$ process and kinetic study, Water Res. 38 (2004) 2782-2790.

[10] S. Kataoka, D.T. Tompkins, W.A. Zeltner, et al., Photocatalytic oxidation in the presence of microwave irradiation: observations with ethylene and water, J. Photochem. Photobio. A: Chem. 148 (2002) 323-330.

[11] S. Horikoshi, H. Hidaka, N. Serpone, Environmental remediation by an integrated microwave/UV-illumination method. 1. Microwave-assisted degradation of rhodamine-B dye in aqueous $\mathrm{TiO}_{2}$ dispersions, Environ. Sci. Technol. 36 (2002) 1357-1366.

[12] V. Círka, M. Hájek, Microwave photochemistry. Photoinitiated radical addition of tetrahydrofuran to perfluorohexylethene under microwave irradiation, J. Photochem. Photobio. A: Chem. 123 (1999) 21-23.

[13] P. Klán, J. Literák, M. Hájek, The electrodeless discharge lamp: a prospective tool or photochemistry, J. Photochem. Photobio. A: Chem. 128 (1999) 145-149.

[14] S. Horihoshi, H. Hidaka, N. Serpone, Environmental remediation by an integrated microwave/UV-illumination technique 4. Non-thermal effects in microwave-assisted degradation of 2,4-dicholorophenoxyacetic acid in UV-irradiated $\mathrm{TiO}_{2} / \mathrm{H}_{2} \mathrm{O}$ dispersions, J. Photochem. Photobio. A: Chem. 159 (2003) 289-300.

[15] M. Stylidi, D.I. Kondarides, X.E. Verykios, Visible light-induced photocatalytic degradation of Acid Orange 7 in aqueous $\mathrm{TiO}_{2}$ suspensions, Appl. Catal. B: Environ. 47 (2004) 189-201.

[16] M.A. Behnajady, N. Modirshahla, M. Shokri, Photodestruction of Acid Orange 7 (AO7) in aqueous solutions by $\mathrm{UV} / \mathrm{H}_{2} \mathrm{O}_{2}$ : influence of operational parameters, Chemosphere 55 (2004) 129-134.

[17] M. Muruganandham, M. Swaminathan, Photochemical oxidation of reactive azo dye with $\mathrm{UV}-\mathrm{H}_{2} \mathrm{O}_{2}$ process, Dyes Pigments 62 (2004) 269275.

[18] F.S. García, J. Luciano, A.L. Capparelli, A.M. Braun, E. Oliveros, Evaluations of the efficiency of photodegradation of nitroaromatics applying the $\mathrm{UV} / \mathrm{H}_{2} \mathrm{O}_{2}$ technique, Environ. Sci. Technol. 36 (2002) 39363944.

[19] P. Mûller, P. Klán, V. Cíkva, The electrodeless discharge lamp: a prospective tool for photochemistry. Part. Temperature- and envelope materialdependent emission characteristics, J. Photochem. Photobio. A: Chem. 158 (2003) $1-5$. 